\title{
Design Teams as Change Agents: Diplomatic Design in the Open Data Movement
}

\author{
Misa Maruyama \\ University of Hawaii at Manoa \\ misattm@hawaii.edu
}

\author{
Sara Douglas \\ University of Hawaii at Manoa \\ sarad@hawaii.edu
}

\author{
Scott Robertson \\ University of Hawaii at Manoa \\ scottpr@hawaii.edu
}

\begin{abstract}
Designers and developers who want to participate in the open data movement should be more than technical experts; they should also be change agents. Realizing open data's promise of innovation and entrepreneurialism requires the support of diverse stakeholders. Government agencies must release accessible and useful data; developers must use the data to build tools; and citizens must adopt the technology.

The interests of one group may come at the expense of another. For this reason, we examine the usefulness of a diplomatic design approach, which focuses on the art and practice of conducting negotiations using specialized techniques. We conducted an exploratory case study on a national nonprofit fellowship program as it worked to design not only technology but also organizational and social change in the context of a digital government engagement.
\end{abstract}

\section{Introduction}

A growing number of governments have joined the "open data" movement, which refers to the publication of "raw, authoritative, or unprocessed information that allows individuals to reach their own conclusions" [31]. Information communication technologies have increased governments' ability to disseminate vast amounts of data, allowing developers to build public-facing applications [5, 25]. But this young movement faces the special challenge of harnessing the collective participation of city agencies, third-party developers, and end users.

A new breed of professionals who understand diplomatic design is needed. They should not only have "hard skills" such as programming or design expertise, but also "soft skills" such as communication, negotiation, persuasion and change management. These change agents must be willing to transcend typical project development processes to explore how government operates, what stakeholders may gain from participating and what they stand to lose.

This exploratory case study examines how a design team used one such approach in one of eight U.S. cities selected to participate in the Code for America (CfA) program in 2012. CfA is a national, nonprofit fellowship program. The fellowship matches civic-minded technologists with cities for one year to build technological solutions from government data.

This paper begins with a review of existing literature on open data and change agency. Scant research exists on change agency in the open data movement, a gap this study aims to help address. We then describe the research site and method used for data collection and analysis. We review the process undertaken by the Code for America team during a five-week visit and discuss the challenges they encountered. We conclude with implications for practice.

\section{Literature review}

The open data movement began in the 1990s, with projects such as Census.gov in 1996 [31]. President Obama thrust the initiative into the national limelight when he signed the "Open Government Directive" in 2009, requiring federal agencies to publish "high- value datasets" in an "open format." According to the Data.gov website, its primary purpose is to "improve access to Federal data and expand creative use of those data beyond the walls of government by encouraging innovative ideas (e.g., web applications)." This reflects an increased emphasis on liberating data not only for transparency's sake but also for use by third-party developers [5, 25].

Book publisher and technology blogger Tim O'Reilly [23] uses the term "government as a platform" to describe how governments can harness the power of open data via the Internet. According to O'Reilly [23], governments should build a public infrastructure for data, allowing developers with diverse skills, resources and motivations to build myriad tools - just as Apple provided a framework upon which programmers could build more than 
500,000 iPhone applications. Researchers have supported this proposition, saying the market allows novel and unpredictable ideas to bloom unrestricted by government's cumbersome procurement policies $[5,25]$.

However, not much literature exists on how to realize this vision, in part because the open data sphere represents a new frontier in e-government. On the one hand, researchers have sounded a call for more open government data [5], agency compliance to open government initiatives [4], and resolution of complex tensions inherent in information-based transparency $[12,13]$. On the other hand, few studies have looked at how to pragmatically foster collaboration on open data among diverse stakeholders with conflicting interests.

We argue that fostering an open data eco-system requires IT specialists who are skilled change agents, not only technical experts. A change agent is defined as "someone responsible for initiating and maintaining a change effort" [16]. Change agents are either internal [6] or external to the client system [16]. There is extensive literature on change agency, including the content of change, contextual forces of change, change outcomes and the process of change [1]. Many metaphors have been used to describe the role of the change agent, including missionary [19, 22], witch doctor [9], mythmaker [10], and diplomat [28].

To equip change agents with skills to manage IT projects, Kendra \& Taplin [16] recommend focusing on six common competencies including communication, teamwork, process management, leadership, training, and continuous learning. Each competency comprises a set of skills. For example, leadership skills include directing, being patient, sensitivity, diplomacy, empathy, political savvy, sales and assertiveness.

Many models exist to guide change agents through the change process, including Lewin's [20] model of phases of change: unfreezing, moving, freezing. We highlight the following subset of Kotter's [18] change model, which parallels themes that we found in this study:

- Create a powerful guiding coalition: Recruit a group with enough power to make the change happen.

- Craft a vision: Be able to concisely relay vision to get curiosity and understanding.

- Communicate the vision: Use a lot of communication to capture "the hearts and minds of the troops."

- Create strategic short-term wins: Get quick wins to maintain momentum.

Caldwell [6] offers four models of change agency: (1) the leadership model, a top-down approach where change begins at the apex of an organization; (2) the management model, where middle level managers effect change; (3) the consultancy model, where internal or external consultants facilitate the change process; and (4) the team model, which envisions change agents as teams of managers, employees, specialists and consultants. The team model views change agency as a collaborative process, due, in part, to "a growing disillusionment with the over-emphasis on charismatic or heroic leadership" [6]. This bottom-up approach is often viewed as more effective because everyone involved can work together to renew change [6].

A comparison can be drawn between Caldwell's [6] team model and participatory design in HumanComputer Interaction [2], which has roots in Scandinavia's workplace democracy movement in the 1970s [3]. Participatory design practitioners establish technological requirements and build prototypes within the end users' environment [7]. While approaches vary, researchers and practitioners share the belief that users' knowledge, voices and rights are valuable to the design and development of technologies [21].

However, neither participatory design nor the other change agency models mentioned above fully satisfies the needs of designers and developers working in the open data sphere. Participatory design focuses on the design of specific products and services [21] - but does not necessarily consider the social, organizational and ideological consequences of the technology that is being deployed. Caldwell's team model considers social and organizational dynamics but is focused on change within a single organization. In the nascent open data movement, a new form of design is needed that not only addresses how to design a technological product, but also considers how to effect social and organizational change within and outside of an organization.

\section{Research design and methods}

Our case study investigates the collaboration between Code for America (CfA) and the city. We chose the site for its rich context, which allowed us to explore the role of participatory design and change agency in the open data movement. A single case can be used when it is unusually revealing or allows for rare access [14]. We felt the nonprofit fellowship program represented a novel approach to opening data: civic-minded technologists parachuting into the wilds of city hall to use technology to reinvent 
government and citizenship. As far as the authors are aware, this is a new form of public service in government.

Moreover, CfA's collaboration with stakeholders inside and outside of government provided an opportunity to explore change agency not only within a single organization, but also across organizations and communities. Because CfA only works with municipal governments, this case provides a way to understand how the open data movement unfolds on the local level.

Our unit of analysis was the individual or role Our epistemological approach was hermeneutic and interpretive, which stems from the belief that people act based on their interpretations of the world [17, $11]$.

\subsection{Research site}

At the time of this study, CfA was in its second year. It had expanded from three cities in 2011 to eight cities in 2012. The 26 fellows in 2012 were chosen from 550 applicants. The 2012 cities included Austin, TX, Detroit, MI, Chicago, IL, Honolulu, HI, Macon, GA, New Orleans, LA, Philadelphia, PA, and Santa Cruz, CA. We observed and interviewed one team of three fellows during residency in its assigned city, hereafter referred to as "the city." The CfA team we observed comprised a programmer, a graphic designer and a user experience designer.

\subsection{Program background}

CfA was modeled after Teach for America, a program that recruits and trains college graduates to teach for two years in underprivileged public schools [30]. CfA's 2012 fellows have experience in design, development or government. The fellows spend the first month of their fellowship at CfA's headquarters in San Francisco, where they receive a crash course in municipal government, learn from experts in tech, and receive technical and diplomacy training. After the orientation, each of the eight teams travels to its assigned city for five weeks to learn about the city and identify opportunities.

In its guidebook, CfA describes four phases of the fellowship program: (1) a preparation phase; (2) a four-week training and orientation phase; (3) a fiveweek city residency phase; (4) a seven-month build phase; (5) a transition phase to complete projects and hand them over to local supporters, as well as to identify career opportunities for the fellows.

\subsection{Data collection method}

This paper focuses on the city residency phase. We collected our data using semi-structured and unstructured interviews, participant observation and document analysis. The primary data source was more than 40 hours of participant observation. This included observing the fellows as they interviewed city employees, technologists, community activists and journalists. The deputy director of the city Department of Information Technology "sponsored" the research study. He sent an e-mail description of the study to interviewees and asked them to contact the research team if they objected to being observed. In all, 22 interviews were observed and recorded in field notes. Each interview lasted about an hour. As a participant observer, the first author was able to view the creative process from the developers' perspectives. The abundant access allowed for data collection that would not have been possible as a passive, outside observer.

Our interpretive approach pertains only to the perceptions of the design and development team as it related to their design process, rather than the sociotechnical system as a whole. To delve further into these perceptions, interviews were conducted with the three fellows and CfA's founder, Jen Pahlka. Interviewees were asked to reflect upon the mission of CfA, the design and development process, how success would be defined and potential challenges. Interviews were audio recorded and transcribed for accuracy and coding purposes. During the time on site (three to five days a week over five weeks), many informal discussions were held with project participants. These conversations were recorded in field notes, usually after the day's fieldwork. To triangulate, we also analyzed artifacts such as the fellows' online calendar, meeting notes and guidebook.

Another data source was observation of community events related to CfA's engagement, including a hackathon, a mayoral press conference, a city employee meeting about the city's social media use, a presentation at a local co-working space and a grassroots assembly of about 100 people. Portions of the events were audio recorded when possible, and the remainder was documented in detailed field notes

\section{Data analysis and findings}

We analyzed our data - approximately 120 pages of transcripts and field notes - using a coding method similar to Glaser's [15] grounded theory approach. We conducted the initial open coding process using a qualitative data analysis tool, Atlas.ti. Through iterative coding, merging of codes and linking of 
concepts, we arrived at three overarching themes related to CfA's engagement: (1) the program's mission, (2) the fellows' role as change agents and true believers, and (3) their design and development process.

\subsection{CfA's mission}

CfA is designed to motivate the web generation to give back. Pahlka said in an interview that she got the idea for the program while working with O'Reilly, who conceived of "government as a platform" [23] The seed idea sprouted when Pahlka's friend, who worked for local government, asked Pahlka to help him recruit developers to write apps for his city. The challenge was to find a way to motivate young, talented technologists to leave potentially profitable positions for the public sector. Pahlka said one day they came up with an idea:

"We were talking about Teach for America and thought that might be one way you can do this because people will do something as a chance to give back if they believe in the idea. They'll do it for glory and satisfaction of having done something good that they won't do for money. And so we decided to start this fellowship program."

It seems the program began with a pragmatic question: How can we attract talented developers to build civic software for local government? But the chosen solution - a fellowship program branded as a new form of public service - allowed them to recruit not only talented technologists, but also individuals ready to be change agents.

\subsection{Role: Change agents as true believers}

Our observations revealed that the fellows passionately believed in their work and its purpose. They spread their ideology about government, public service and citizenship with missionary-like zeal. Each of the three fellows said in separate interviews that they joined the program because they wanted to dedicate "a year of their lives to public service." One fellow, a U.S. Marine who had been deployed to Iraq, said she was looking for a new way to give back to her country after her service in the military. Another fellow who worked as a user experience designer in a large, multi-national technology company said she was searching for greater purpose in the year leading up to the fellowship:

"I spent much of 2011 trying to figure out what it was that I wanted to do next ... I knew that I wanted to make more of a difference. But I didn't know what exactly that would mean in terms of the skills that I had and the scale at which I wanted to apply them."

The third fellow was working as a programmer in Colorado. He says his desire to do something more meaningful led to him to consider leaving his job for CfA:

"I'd been working there for a while, built some software, released some stuff. So I was pretty happy with what I had already accomplished there. But at the same time, it was, I don't know. It wasn't exactly ... rewarding?"

He says two former fellows in the 2011 fellowship addressed his chief concern:

"The question is, it all sounds great, but on the outside you don't know. And you know this is a new organization; they're trying to do something helpful. But is it legit? Are they actually doing something good or is this just yet another thing that people are involved in? So they, kind of, they were able to show me that, yes, this was actually very productive, that it has supported different cities, and that they're actually getting access to making that change."

Of course, this is not to say that the fellows participated out of altruism alone. The program provides a mentorship program that offers access to some of the biggest names in technology. Also, one metric for the program's success is the fellows' ability to land a job after the fellowship; the program attempts to secure an offer for at least 80 percent of its participants.

Still, the fellows were united behind a common desire to make a positive difference. We observed that the desire to effect change and the belief in CfA's philosophy were necessary as the fellows faced daunting challenges in trying to "liberate" government data and improve the relationship between citizens and government.

\subsection{Process of change}

Based on our observations of the team's process, we identified several diplomatic design strategies used to effect change. They include:

- Provide training in diplomacy.

- Employ participatory design.

- Promote innovation by demonstrating processes to follow.

- Develop concrete examples to publicize success 
and maintain momentum.

- Create an alliance of supporters.

4.3.1. Training in diplomacy. The CfA fellows' training focuses on soft skills to allow the fellows to be seen "as partners, instead of outsiders" in their host cities. Their training includes both "hard skills" and "soft skills." Hard skills include development processes, knowledge of design principles and user research. Soft skills comprise diplomacy, negotiation, communication, team building, change management principles and project management. One day of training is devoted to a course delivered by the Program on Negotiation at Harvard Law School. One fellow says he didn't expect such an emphasis on soft skills:

"My coming into it, I probably thought it would be more about programming. And really, The Institute, I haven't programmed as little as I have in the last three-month period in, like, most of my life."

Training in diplomacy is needed early in the process to provide change agents with the soft skills they will need. Often the needs of different stakeholders contradict. Discussing technology requirements with various groups of stakeholders in the open data sphere is like traveling to distant lands, each with its own people, culture and history. If the designer is trained in diplomacy, she can negotiate requirements among the groups in a strategic and tactful way.

4.3.2. Participatory design. The fellows interacted with more than 100 city department managers, city employees, technologists, community organizers and academics. The most commonly asked question was: If you could set one goal for us, what would it be? This often triggered apparent enthusiasm and active brainstorming among interviewees.

The fellows also observed a neighborhood board meeting and answered calls at the city's hotline for non-emergency information requests and complaints. Toward the end of the city residency, the fellows encouraged dozens of technologists and citizens to participate in a brainstorming session at a public assembly. During this workshop, they asked the audience to break into smaller groups to discuss topics - such as transportation and government dataand brainstorm possible projects. Each group subsequently presented its ideas to the larger group.

While the CfA team did not explicitly state they were using participatory design, we would argue they used this approach with certain user groups - for example, city employees and technologists.
Participatory design is an HCI approach based on a collaborative, mutual learning relationship between the uses and designer to design an interface [8]. According to Carroll et al. [8], user participation in participatory design projects can progress over time. Users often begin as practitioner-informants, whom are interviewed and observed by designers. They can progress to analysts, who are actively involved in establishing requirements; designers, who assist in the design and prototyping process; and coaches, who teach other users about the technology [8]. Observations showed stakeholders took on practitioner-informant, analyst and designer roles. Participatory design is used to allow the users' voice into the process, which we argue is a necessary component in achieving success in this domain.

\subsubsection{Demonstrate innovation in government} through design processes. The fellows' design process was modeled on an approach described in the book "The Lean Startup" by Eric Ries [24]. The approach is designed to provide a lean and agile way to learn what users need, choose the right project, develop the product and iterate the design. A cornerstone of the approach is the "minimal viable product," which provides what the user needs and no more. Ries [24] encourages designers and developers to pivot quickly, rather than spending additional resources on an idea that wasn't quite right to begin with. During a presentation to programmers in the host city, O'Reilly suggested bringing the philosophy to government:

"You look at the startup world. How many startups fail? So, like, if Code for America does 20 or 30 projects a year, and 25 of them fail, that's probably a pretty good record. That's what VCs expect. You know, because the five of them succeeded. Even the ones that fail are the seeds of something else. Would Facebook exist if Friendster hadn't been there first and failed? If Plaxo hadn't been there first and failed? You look at all of the people who were taking a run at some kind of social networking idea and didn't get it right before Zuck came along. And I think it's really important to understand this is bringing the same kind of creative destruction - one friend of mine who is in Congress calls it "Schumpeterian waste" - to government. Government tries something and fails and keeps doing it because, by God, we got so much sunk cost. So you see these projects where it's like we spent $\$ 680$ million, and it's still not working. And you go, how do you do that? Well, it's because you can't say that one failed; let's move on and try something different." 
The Lean Startup philosophy is not about taking unwarranted risks, but rather being lean and agile enough to modify or abandon a project that's not working [24]. CfA's approach is designed to bring these values of innovation to government, as one fellow describes:

"Code for America is very much about trying to change the way governments view working on these types of applications, view working with the public, I think. And so in that, like, if you can get cities to realize that things can be done inexpensively, and it can be done well, they can involve the public in actually discussing ideas and shaping policy in new and innovative ways, I think that is what we're looking for."

We discuss the lean and agile process here not because we recommend it as a preferred development process. Rather, we discuss the fellows' use of the approach to underscore how they effected change not only by building technology but also by demonstrating an innovate process to show stakeholders how change might be possible.

4.3.4. Develop concrete examples. A critical part of creating organizational change is being able to communicate an effective vision succinctly and compellingly [18]. The fellows communicate their vision by building things. Their applications serve as symbols for possible change rather than a comprehensive solution - a representation of an abstract concept rather than a true panacea. One fellow describes this strategy:

"It's less about the applications; we want the applications, like, to be useful. But it's something we develop in less than a year. It's, you know, something that probably doesn't have a gigantic impact - it might have some - but it's not the biggest, best application in the world. What we want is for cities to consider how they use software, how they interact with citizens and how they can be innovative in this space."

"If you were really trying to change government on a large scale, you would have far more than three people for one year, right? So we're not trying to get in there and say, 'Let's do everything.' We're trying to get in and say, 'What are a couple of examples of things that we could do that could demonstrate the world that we want to live in, demonstrate the vision for the future?'" - CfA's founder
To encourage buy-in, the fellows frequently told stories about applications built by the previous year's fellows. They also customized previous CfA apps for the city. One example was the Adopt-a-Siren application, which was based on Adopt-a-Hydrant from a previous engagement.

The Adopt-a-Hydrant app allows users to name an adopted fire hydrant and receive a text reminder when it is time to shovel it out from the snow. The fellows we observed adapted the Adopt-a-Hydrant application to Adopt-a-Siren, an app that sends alerts to volunteers prior to tsunami siren tests so they may report malfunctions. Using demonstration projects is a critical strategy in the diplomatic design approach.

Concrete examples are not only symbols of change. They can also serve as quick wins to generate publicity, rally supporters and maintain momentum. Because change is typically a slow process, supporters need short-term goals and victories [18]. The strategy evokes change by bringing together diverse groups, rallying them around symbols that represent innovation, civic engagement and efficient government.

4.3.5. Create an alliance of supporters. Sometimes the fellows acted as a hub for a network of existing change agents - rather than as initiators of change themselves. The fellows were connected with an alliance of supporters within the city, which included city employees, technologists, politicians and citizens. The fellows added value to the alliance by introducing enthusiastic supporters within the city to each other and connecting local change makers to their counterparts elsewhere in the U.S.

Before the fellows' residency, the effort to encourage innovation in the city was well underway. The city's Department of Information Technology deputy director successfully applied to a digital cities survey, and the city received the top award for innovative projects such as a free wireless Internet service. With the support of the mayor, the deputy director also customized an app that allows citizens to report non-emergencies on their smartphone. The city hired a longtime community organizer as a parttime contractor to coordinate several events in the months leading up to the CfA engagement. The events included CityCamp, an idea-generating assembly of citizens and technologists, and the city's first hackathon, a 24-hour competition that challenged local developers to build apps from city data. Two of the apps conceived during the hackathon were released publically, with help from the city and the CfA team.

The fellows capitalized on momentum that existed before their engagement. Their contribution 
to the extant change agency was to connect people who normally wouldn't interact, as Pahlka explains:

"Because the fellows come in with a sort of curiosity and $a$, sort of, almost naiveté around how government works, they go and interview a lot of different people and make connections that if you kind of are in city hall, and you already know what you're doing, you don't need to interview those people... So they have this - I wouldn't call it a side effect but an intended side effect of breaking down those silos. And it's silos within the institution of government, and it's silos between the community and government. And the key there is that this could happen without them once you sort of get the ball rolling. [A city employee's] quote was, 'the fellows in [the city] were like mysterious strangers that came in and showed his staff that they can do this themselves, that they had the magic in them.",

Again the fellows' biggest contribution is not the technology per se, but the demonstration of a process. Here, the process refers to the manner in which the fellows connect a network of supporters who can collaborate on projects and rally others to the cause. The team built on an existing alliance to allow selfsustaining renewal, reinventing and expansion of change after the fellows' departure. This reflects Kotter's [18] recommendation to build a coalition of change agents who come together to achieve a shared vision of excellence and revitalization.

\section{Discussion}

Analyzing these three overarching themes (CfA mission, roles and change process) reveals several observations. Propelling the open data movement is both a technique and an art. It requires a blend of technical skills and change agency skills to negotiate the meanings of relationships, symbols and stories. CfA's public service model and recruitment strategy attracts applicants who are not only skilled designers and developers but also change agents. Armed with their faith in government and citizenship, the fellows are able to reach out to diverse groups and individuals using a diplomatic design approach.

The first step in applying such an approach is to provide soft skills training such as negotiation, communication and persuasion. This reflects several of the recommendations Kendra and Taplin [16] make about the common competencies a change agent should have.

The second step is to employ a participatory design process that incorporates the voices of stakeholders and users. The third and fourth steps include evincing the value of innovation through design processes and developing concrete examples to represent the feasibility of an abstract idea. The final step is to develop a coalition of change agents who will renew, reinvent and expand change.

\section{Challenges}

While we believe this approach has great merit, CfA still faced daunting challenges. Some of the issues include gaining access to the data, identifying the right project, finding time to speak with end users and representing the city's unique local culture.

\subsection{Getting access to the data}

Our coding of the qualitative data revealed many prickly issues related to acquiring government data. Perhaps the most common challenges were poor data quality and the amount of work needed to clean it up, as one fellow explains:

"Where they already have it easily accessible, they're really good about it. They'll publish it readily. The [public] art data set was a clear data set that we could grab, and, you know, obviously like no big impact in anything there. So, that was simple. Where it's harder for them to, put together or it requires more resources to do, that's definitely a road that we have to cross."

The fellows said their goal was to "liberate" data in a machine-readable format to allow other developers to build tools from the information. But some data were distributed across different systems in conflicting or unusable formats. When asked about the traffic data, one city employee quipped:

"You're looking for a stream of data, and you're not going to find it. The city is analogue."

Another issue was reluctance to release based on concern for data misinterpretation. One department manager worried that the public would misunderstand how projects were prioritized and why work crews are assigned to some areas first:

"The government doesn't do it in the way that people understand."

A city employee in a different department raised the issue of privacy, citing concerns about releasing employees' personally identifying information. Besides personnel data, crime data is probably the most sensitive information the team tried to access. 
The city's police department displays crime information using a map application but did not release the raw data. One interviewee reflected upon the situation:

"I don't actually know what's so sensitive about it because they publish it online anyway, at least through another company. So, I think it's just convincing people that opening data is good because other projects can happen with that, other people can take a look at that data and maybe they'll find something interesting. Maybe people are scared of what that interesting thing is, that's also quite possibly true, so they like their lockdown environment."

Many of the challenges we mentioned are common in information-based transparency initiatives in the public sector [12]. To deal with these tensions, Dawes [12] recommends balancing data stewardship and usefulness. Data stewardship refers to a conservative position that makes data care and integrity top priorities; usefulness refers to ensuring the data is valuable to users [12]. The former emphasizes averting risk while the latter promotes creative use of the information inside and outside of government. While they seem antithetical, Dawes [12] says the principles are complementary because an increased trust in government data will encourage people to develop innovative tools.

\subsection{Identifying the right project}

The CfA fellows' interviews with city employees revealed dissatisfaction with the city website. City employees described the website as uninformative, unattractive, static, "very cumbersome," "very hard to use," "very dry, not too exciting," "inconsistent," "just terrible," and "really Mickey Mouse." One problem is that the website is organized by city department, an organizational structure that is not well known to many citizens.

One CfA fellow was in favor of a complete overhaul of the website but worried about the feasibility of the project:

"The site is a huge monster. It's a huge project, and [the city's Department of Information Technology director] told us even just doing the architecture for it - like mapping it out - would take a lot of effort and a lot of time. I feel like if we do it, we're going to end up doing only that."

The fellows eventually opted to create [City] Answers, which would provide a search interface for government information. The choice reveals one of many tradeoffs observed between feasibility and the desire to make sweeping change.

\subsection{Speaking with end users}

Perhaps the most significant challenge was balancing the need to get stakeholder buy-in with the ability to speak with average citizens. Of the five weeks spent in the city, about 4.5 weeks were dedicated to speaking with mostly city employees, technologists and business owners. Much less time was spent speaking with average citizens.

"I feel like they could have played more of a role. I think in some cases it's kind of hard because you're balancing a lot of different aspects: like what the city wants to do, first, and then what you can really, you know, what data is available to you, what process is available ... is anyone going to support and continue the project that you're working on ... So we did get feedback from citizens, and I think we tried to use quite a bit of that. But it's kind of hard to balance that against what will the city maintain." - Fellow

Few - if any - interviews conducted by the fellows were with people who had no experience with technology, community organizing, government or academia.

"That is one thing I feel like did not happen ... I mean Code for America had asked [city contacts] to set up meetings with city staff the first two weeks. And that just was, with so many departments and everything, it just kind of became a first about three or four weeks." - Fellow

The fellows had back-to-back meetings at city hall from 8 or 9 in the morning until about 6 or 7 at night. They often spent their evenings at meetups with local technologists or at community events. The busy schedule crowded out the fellows' ability to speak with community members who were unassociated with government or technology.

It might have also affected the fellows' ability to reach out to indigenous people. Of the city's population of 950,000 people, about 9.5 percent are indigenous [29]. However, the fellows had few meetings with representatives from the indigenous people's community. Yet, these interviews were key, allowing the fellows to learn firsthand about the indigenous people's history and discover that the interviewees' notion of civic engagement diverged from theirs. The three fellows later said they had been deeply impacted by the interviews, as one 
fellow explains:

"I mean we had heard about this, thought about it, but thought about it academically. You know, that native [people] had suffered so much, etc. So there is a mistrust of government, yeah sure. But you know we weren't thinking along those lines when we were partnering, when we were talking about the notion of citizenship ... and then to really have that be driven home yesterday and this morning was really helpful ... Those words took on a new light. You know. And also, that, why are our neighborhood board meetings mostly white? ... It's because this is a very Western notion of democracy."

This is not to say there was no exposure to the indigenous culture at all. On the fellow's first day in the city, the city contact arranged for an all-day excursion to cultural sites and a historical museum. But the fellows said their schedule left little time to reconsider these issues until the very end of the residency, when they met with informal representatives from the indigenous people's community. The city contact explains his perspective:

"I thought I had said in the beginning that I really want to focus on something that's [related to the indigenous people]. And I want this thing to be, to take into account, [the state] and have a native feel ... That's why we went to [the] museum, and we did all these things when you first got here. And we haven't really talked about it again since then. But I'm kind of glad that you guys had this meeting because it kind of reminded us of why we're here. We are a guest in this culture, right. And you know I think it's only proper to think of ourselves as guests, even us guys who have lived here and for those guys that are born here."

The city's unusual ethnic and cultural diversity makes for a difficult challenge. Countless communities exist, and it would be almost impossible to reach out to representatives from each group during a five-week period. The fellows seem to appreciate the need to reach out to end-users and understand minority cultures, but their schedules couldn't accommodate the need. The city interviews and meetings were necessary to acquire the data needed to develop the applications, but - in the end the question remains: For whom were the apps intended for in the first place?

One approach that may tie the development process to the needs of the local community is community informatics. Community informatics (CI) researchers study the design and implementation of information communication technologies (ICTs) in local communities [27]. It's an approach that begins with the needs of local communities and considers issues of social justice - such as race, power, class and disability [27]. CI researchers are highly critical of technologically deterministic perspectives, such as the belief that technology will lead to positive consequences in every social context in which it is deployed. This approach sensitizes the researcher or practitioner to ICTs' influence on communities and the value of participatory community change [27].

\section{Conclusion}

Open data advocates view technology as a way to reinvent government and citizenship. This paper suggests that technologists who work in the space not only be skilled in design and development methodology but also change agency, diplomacy and grassroots advocacy. Our case study is intended to explore CfA's unique method of combining participatory design and change agency, which we call diplomatic design. The case is revelatory in that the fellows' ultimate goal is effecting social change, and the technology they develop is only a means to that end. They use specialized techniques in the art and practice of uniting diverse stakeholders behind a shared mission - a diplomatic design approach that may be applied to similar initiatives in the open data movement.

\section{Acknowledgements}

This material is based upon work supported by the National Science Foundation under Grant No. IIS1064852. Any opinions, findings and conclusions or recommendations expressed in this material are those of the authors and do not necessarily reflect the views of the National Science Foundation.

\section{References}

[1] Armenakis, A., Harris, S., \& Feild, H. (1999). Paradigms in organizational change: Change agent and change target perspectives. In R. Golembiewski (Ed.), Handbook of organizational behavior. New York: Marcel Dekker.

[2] Arias, E., Eden, H., Fischer, G., Gorman, A., \& Scharff, E. (2000). In J. Carroll (Ed.) Human-Computer Interaction in the New Millenium (pp.347-372). New York, NY: ACM Press Books.

[3] Bodker, S., \& Pekkola, S. (2010). A short review to the past and present of participatory design. Scandinavian 
Journal of Information Systems, 22(1), 45-48.

[4] Bertot, J., McDermott, P., \& Smith, T. (2011). Measurement of Open Government: Metrics and Process. 45th Hawaii International Conference on System Sciences, 2012, 2491-2499.

[5] Brito, J. (2008). Hack, mash \& peer: Crowdsourcing government transparency. The Columbia Science and Technology Law Review, 9, 119-157. Retrieved from http://www.stlr.org/html/volume9/brito.pdf

[6] Caldwell, R. (2003). Models of Change Agency: a Fourfold Classification, British Journal of Management, 14, 131-142.

[7] Carroll, J. (2003). HCI Models, Theories and Frameworks: Toward a Multidisciplinary Science. San Francisco: Morgan Kauffman Publishers.

[8] Carroll, J., Chin, G., Rosson, M., \& Neale, D. (2002). The development of cooperation: Five years of participatory design in the virtual school. Human-Computer Interaction in the New Millenium, 373-393.

[9] Clark, T. \& Salaman, G. (1996). The management guru as organizational witchdoctor, Organisation Studies, 3(1), 85-107.

[10] Clark, T., \& Salaman, G. (1998). Telling tales: Management gurus' narratives and the construction of managerial identity, Journal of Management Studies, 35(2), 137-161.

[11] Davidson, E. (2006). A technological frames perspective information technology and organizational change, The Journal of Applied Behavioral Science, (42)1, 26-39.

[12] Dawes, S.S. (2010) Stewardship and usefulness: Policy principles for information-based transparency. Government Information Quarterly, 377-383.

[13] Dawes, S.S., \& Helbig, N. (2010). Information Strategies for Open Government: Challenges and Prospects for Deriving Public Value from Government Transparency, Electronic Government: Lecture Notes in Computer Science. M.A. Wimmer et al. (Eds.), 50-60.

[14] Eisenhardt, K., \& Graebner, M. (2007). Theory building from cases: Opportunities and Challenges, Academy of Management Journal, (50)1, 25-32.

[15] Glaser, B. (2002). Conceptualization: On theory and theorizing using grounded theory. International Journal of Qualitative Methods, 1(2), 23-38.

[16] Kendra, K., \& Taplin, L. (2004). Change agent competencies for information technology project managers. Consulting Psychology Journal: Practice and Research, 56(1), 20-34.
[17] Klein, M., \& Myers, M. A Set of Principles for Conducting and Evaluating Interpretive Fields Studies in Information Systems. MIS Quarterly, 23(1), 67-94.

[18] Kotter, J. P. (1995). Leading change: Why transformation efforts fail. Harvard Business Review, 73(2), 59-67.

[19] Lapsley, I., \& Oldfield, R. (2001). Transforming the public sector: Management consultants as agents of change, The European Accounting Review, 10(3), 523-543.

[20] Lewin, K. 1947. Frontiers in group dynamics. Human Relations, 1, 5-41.

[21] Muller, M. (2002). Participatory design: The third space in HCI, Human-Computer Interaction Development Process, 165-185.

[22] Neu, D., \& Ocampo, E. (2007). Doing missionary work: The World Bank and the diffusion of financial practices, Critical Perspectives on Accounting, 18(3), 363389.

[23] O'Reilly, T. (2010). Open Government: Collaboration, Transparency, and Participation in Practice. D. Lathrop and L. Ruma (Ed.). Sebastopol, CA: O'Reilly Media.

[24] Ries, E. (2011). The lean startup: How today's entrepreneurs use continuous innovation to create radically successful businesses. New York, NY: Crown Business.

[25] Robinson, D., Yu, H., Zeller, W. P., \& Felten, E. W. (2009). Government data and the invisible hand. Yale Journal of Law and Technology, 11(160).

[27] Stillman, L., \& Linger, H. (2009): Community Informatics and Information Systems: Can They Be Better Connected? The Information Society: An International Journal, 25(4), 255-264.

[28] Taylor, A. (2008). Leadership in sustainable urban water management: An investigation of the champion phenomenon. Industry report for the National Urban Water Governance Program, Monash University. Melbourne, Victoria: Monash University.

[29] U.S. Census Bureau. (2010). State \& county Quickfacts: Honolulu County, H.I. Retrieved June 13, 2012, from http://quickfacts.census.gov.

[30] Veltri, B. (2008). Teaching or Service?: The SiteBased Realities of Teach for America Teachers in Poor, Urban Schools, Education and Urban Society, 49(5), 511542.

[31] $\mathrm{Yu}, \mathrm{H}$. and Robinson, D. Forthcoming. The New Ambiguity of 'Open Government, UCLA Law Review Discourse. 